\title{
Role of The Family in Entrepreneurship Develoment in Nepali Society
}

\author{
Dr. Sushil Kumar Pant
}

\begin{abstract}
Entrepreneurship is the engine for social and economic growth of any society. It drives people toward wealth and job creation which leads to better lives for people in the society. There has been growing interest in entrepreneurship research recently. This paper attempted to assess the impact of family in Nepalese society. This was viewed as essential in a country in which more than 125 ethnic communities are found. The findings show that family has some impact in people to become entrepreneurship but it was not strongly substantiated by statistical tests. It was found that entrepreneur's parental profession plays some role in entrepreneurship development in Nepal which was similar to some findings that parental profession plays vital role in the choice of profession in children.
\end{abstract}

Key words: Family, entrepreneurship, entrepreneurship development, Nepali society

\section{Introduction}

Entrepreneurship in a society is dependent upon various factors; socio-economic status of the country being the one of the important one. Economic opportunities available in a country largely determine enterprise creation. If people see opportunities potentially bringing desired returns then they go for it. Hence, economic opportunity is an important reason for entrepreneurial activities. People with entrepreneurial qualities would explore the opportunities created by the economic changes that the society is undergoing. Also the economic uncertainty people face in their present activity, especially in the job, often forces them into an entrepreneurial venture for their economic survival. Moreover, those who are not satisfied with what they are earning from their present job and aspire for a better life tend to enter into creation of enterprises.

There are quite a few other factors that have to be taken into considerations while studying entrepreneurship. Socio-cultural factor is one of them. The study of management practices as well as entrepreneurship is often conducted on the basis of how social and cultural factors influence them. Therefore an attempt has been made in this regard to explore the influence of these factors in entrepreneurship. Questions about factors impacting on the entrepreneurial status of a society are debated in entrepreneurship studies. Factors such as risk orientation, innovative capabilities, technical capabilities, proactiveness, autonomy are considered as major indicators of entrepreneurial capabilities among people. In addition, many researchers have pointed to Culture as an important factor which influences entrepreneurship in a society. Culture is the combination of attitudes, beliefs, values and life styles. All of them contribute to shape an individual's orientation towards entrepreneurship. Individual behavior is important factor which influences whether a person goes on creating a new venture or not. It is also true that one's cognition is influenced by cultural values and social context. 
Role of a family in successful running of a business need not be overemphasized. This is more relevant in the case of entrepreneurial and small scale ventures. Aldrich and Cliff (2003) suggest that a family embeddedness perspective that acknowledges people are part of networks of social relations is more appropriate in the context of entrepreneurship research. Such an approach is particularly important in the context of ethnic minority enterprise where social and family networks have been found to be particularly important. These networks enable ethnic minority entrepreneurs to draw on unique cultural resources or social capital not generally available to the mainstream groups. For example, cheap family labor, pooled savings and access to trusted networks which facilitate trade and provide access to information, thus providing a particular competitive advantage. Such informal networks have also been found to be important as a means of mobilizing resources and generating sales. It is the family and the community that lies at the heart of ethnic firms' social networks. Family and community resources provide with a unique form of social capital important to the establishment, development and the success of a business. Therefore, the impact of the family is obvious as enterprises are established and run in a social setting of which the family plays an important role in it

Entrepreneurs are inseparably linked to their families and rely on their support in pursuing their entrepreneurial endeavors (Rogoff \& Heck, 2003). Family members share a common identity, have strong mutual bonds of trust, and often have opportunities to discuss business ideas (Aldrich \& Cliff, 2003; Ruef, Aldrich, \& Carter, 2003). In fact, the family constitutes one of the most common entrepreneurial teams (Ruef, 2010) and scholars have argued that significant entrepreneurial potential can be found within the family (Nordqvist \& Melin, 2010). The importance of the family as entrepreneurial team is also evidenced by the fact that a substantial share of all companies are founded and run by families all around the world (La Porta, Lopez-de-Silanes, Shleifer, \& Vishny, 1999; Villalonga \& Amit, 2009), such as spousal couples or family members tied together by other types of family relationships (Chang, Chrisman, Chua, \& Kellermanns, 2008; Ruef, 2010).

There are at least three reasons for the family's importance in entrepreneurial outcomes. First, when engaging in entrepreneurial activities, the family constitutes a very specific type of entrepreneurial team. Strong ties in terms of kinship relationships between family members bind the family closer together than any other type of entrepreneurial team (DiscuaCruz, Howorth, \& Hamilton, 2013). Second, the family provides the entrepreneur with a diverse set of resources (Dyer \& Handler, 1994; Sirmon \& Hitt, 2003), which have the potential to impact the individual entrepreneur as well as the family business. Third, family business scholars have argued that the family and the business are intertwined, denoted as family influence (Dyer, 2006; König, Kammerlander, \& Enders, 2013). As the family business is composed of multiple family members, the structural family ties will spill over to the business (Arregle, Hitt, Sirmon, \& Very, 2007).

Hence, family background has been considered as one of the major factors to motivate a person to enter into a business, existing or new. It is believed that if a person is exposed to a family culture where innovating thoughts have been successfully transformed into great business empire or a huge wealth for them children tend to view this as a tradition which they need to take further. This belief inspires many of them to create a separate venture for themselves where they not only inherit their tradition of business success but also have opportunities to prove their mettle. Despite somewhat negative attitude on joint family working as a hindrance in enterprise creation in the western societies, there are ample examples of successful enterprise owned and managed by families in South Asia. Zivetz (1992) states that extended family 'corporations' dominate large scale industry in India 
and are also common among many commercial communities in Nepal. These domestic corporations owe part of their success to their ability to put trusted family members in key business positions. She further states, many businesses are established with the explicit purpose of providing work for unemployed or underemployed family members. Starting a business is often a response to changes in family relationships rather than rational discovery, development and exploitation of business opportunities. Therefore the influence of family in entrepreneurship is considered as an important factor to be explored.

\section{Problems and Objectives}

Taking cues from above discussion, the study aims to explore the influence of social and cultural factors in entrepreneurship in Nepal. The study is designed with a view to explain socio-cultural factors that influenced people entering into entrepreneurship and the degree of impact on them of the factors covered in this research. One of the specific objectives was to assess the impact of family background on entrepreneurship in Nepal.

\section{Data and Methods}

A positivist approach was preferred for this study by using survey method since it helps to make generalizations to large populations from the results. However, non-positivist approach was also adopted through case studies of phenomena with a view to having their deeper understanding on one hand and to supplement the survey study on the other. Hence, both survey and case study methods were used to collect data.

There are two main options in applying survey research method: longitudinal and cross sectional. In a longitudinal survey, the researcher observes research variables over a period of time so as to measure any changes that may occur in those variables. On the other hand, in a cross sectional survey, researcher observes research variables at a particular point of time and collects data relating to all variables simultaneously and studies their patterns. The longitudinal survey, despite its usefulness in some situations, is often considered to be time consuming and expensive. Thus, the longitudinal survey could not be considered as viable research design for this study. Moreover, in view of the type of issues it attempted to address, this research was basically concerned with examining and explaining some variables and their relationships at a particular point of time. Hence, the cross sectional sample survey design was considered to be the appropriate choice.

Several sources of information were searched before selecting the enterprises. It is because there are several agencies in which entrepreneurs register their businesses. For example, private and public limited companies are registered in the Office of the Company Registrar, trading firms are registered in the Department of Commerce, travel and tourism related enterprises are registered in the Hotel Association of Nepal, Nepal Tour Operators Association, Nepal Association of Travel Agents and others. Similarly, businesses also register themselves in concerned municipal offices, chamber of commerce and other agencies. Therefore, ascertaining the exact number of enterprises was difficult. Hence, the study firstly selected the enterprises which were registered with related chambers of commerce and industry as members. However, the sample was not limited to members only. The member entrepreneurs were asked to provide references to other entrepreneurs who would be ready to provide information for the study. The total number of members 
in Nepal Chamber of Commerce was 1600. Pokhara Chamber of Commerce and Industry had 1517 members. Therefore, this was assumed to be preliminary population for the study. However, as mentioned earlier, entrepreneurs not registered with the chamber of commerce and industry were also included hence making total population much bigger than the given numbers.

Though entrepreneurs running large enterprises were not excluded, the focus was on micro, small and medium sized enterprises. In fact, the priority was given to micro and small enterprises. This was because majority of entrepreneurial activities begin and usually conducted in small sizes. Besides, Nepal being an underdeveloped country where most of the entrepreneurs have small amount to invest in a business so the businesses are run in small sizes. Hence, micro and small enterprises were selected for the study.

Stratified judgment sampling method was adopted to choose the sample from the population because the study was designed to include entrepreneurs from various socio-cultural backgrounds. Hence, it was essential to use different strata for sample selection. The strata included both men and women entrepreneurs from both the cities. It also included entrepreneurs from various ethnic groups of Nepal. This was essential because the study intends to identify the effect of gender and ethnic background on the entrepreneurial activities. Other studies have found that both men and women are involved in entrepreneurial activities but they face different types of social situation based on the values, norms and attitudes of the society they live in. Hence, it was felt necessary to explore this aspect in this study, so both men and women were purposely included in the sample.

The study was carried out by purposively selecting 225 entrepreneurs from Pokhara and Kathmandu valley for questionnaire survey. The two places were selected for their importance in Nepal's economy as prominent business centers. Kathmandu is the capital of the country in which main business activities occur. Hence, it was selected as a sample place. Pokhara is Nepal's major tourist destination with substantial business activities. Therefore, the place was chosen for the study. They were also chosen for the obvious reason of easy accessibility. The sample selected was designed to be broadly representative of the geographical distribution of micro and small enterprises in both the places and was designed to include a mixture of men and women and the first- and secondgeneration businesses. By selecting a number of different businesses and entrepreneurs from different backgrounds the study aimed to identify the range of relationships, aspects and issues that might have been important to the businesses. The sampling also used some "snowball method" so that more people from a community and business are covered. This was essential because people from certain community and businesses know each other. By using this method finding the required respondents was a lot easier.

\section{Discussion and Analysis}

\subsection{Role Of Family In Entrepreneurship Development}

An important feature is that Nepalese society is based on joint family system. In most cases, when parents are alive, a family does not break until and unless there is any serious conflict among family members or there is lack of space in the parental home. Senior members of the family are respected and are supposed to be obeyed. This influences a lot while making choice of profession and business. This also applies in business related 
activities. Cultural values also have its root in the economic conditions of the country. Nepal is a developing country and large numbers of its people are poor. In such a society, people are often treated on the basis of their wealth and the power they enjoy from their political and other linkages. This also is believed to have created some hindrance on entrepreneurship development in Nepal.

\subsection{Types of the Family}

Types of family play some role in an individual's choice of profession. It is generally believed that people from nuclear family enjoy the independence of making choice of his/ her profession. However, the support provided by the joint family works as a basis for an individual entering into entrepreneurial activity. Therefore, information on types of family of entrepreneurs was collected and presented below.

The nature of family has an impact in entrepreneurship. There is a notion in the Western countries that the independence offered by the nuclear family creates conducive environment for entrepreneurial activities. They also argue that the joint family culture of the Eastern societies create hindrances for an individual to become an entrepreneur because $\mathrm{s} /$ he has to be in the joint family and has to fulfill other responsibilities which makes entering into entrepreneurship difficult. This seems true in Nepal too as majority of the entrepreneurs mentioned that they lived in nuclear families for their upkeep. Being in a nuclear family asks the head of the family to do something for their families. Therefore, many of them opt for entrepreneurship. However, more than one third entrepreneurs in Nepal told that they lived in joint families. They also had the opinion (asked in a different question) that the joint family had helped them to establish and run their enterprises.

Many researchers have found the impact of family background in entrepreneurship. In fact, there are ample proofs in researches conducted by Western scholars in their social setting that the culture of having nuclear families has strong influence in entrepreneurship in their society. However, in a study by Redding (1980) it was found that unlike the idealized American entrepreneur, characterized by rugged individualism, there is growing evidence that Asian entrepreneurs rely on familial ties in developing their business [Redding, 1980, cited in Thomas, 2000]. This fact is illustrated by the expanding bamboo network of overseas Chinese entrepreneurs in South East Asia and the numerous businesses owned and operated by joint families among the Gujaratis, Parsees, and Marwaris in India, (Thomas, 2000).

An assessment was done by asking the entrepreneurs about the types of their families. This phenomenon was assessed by categorizing their family types so as to know the impact in their entrepreneurial orientation. There were nearly two third of entrepreneurs who came from nuclear families. More than one third came from joint families. It strongly indicates that people from nuclear families are more likely to become entrepreneurs although there were large numbers of entrepreneurs from joint families too. Chi square test was run to establish if there is significant relationship between the two. The calculated value of 47.137 was higher than the tabulated value of 9.488 indicating that either being in a nuclear or joint family does not have much impact in an individual becoming an entrepreneur. This is in contrast to the notion that a person who lives in a nuclear family has more chances of becoming an entrepreneur than the one who lives in a joint family. In fact, it is generally believed that being in a nuclear family creates a sort of insecurity for an individual. Therefore, s/he becomes an entrepreneur in order to create secured 
environment not only for him/her but also to the family. But it does not hold much in the Nepalese society. Hence, the finding needs further exploration with much wider coverage of entrepreneurs before developing an idea in the issue.

\subsection{Parental role in entrepreneurship development}

The role of the parents in development of entrepreneurship is an area of interest in modern day entrepreneurial research. There are various strands on the role the parents and grandparents in influencing their children toward entrepreneurship. Therefore, this was assessed in order to assess the state of influence in entrepreneurship development in Nepal.

Table 1 Role of father's profession in choice of a profession

\begin{tabular}{|l|c|c|}
\hline \multicolumn{1}{|c|}{ Fathers` profession } & Frequency & Percent \\
\hline Business & 60 & 28.0 \\
\hline Farmer & 87 & 40.7 \\
\hline Service & 55 & 25.7 \\
\hline Others & 12 & 5.6 \\
\hline Total & 214 & 100.0 \\
\hline
\end{tabular}

From Table 1 it is clear that large number (40.7 percent) of entrepreneurs told that their fathers were farmers. In a country where vast majority (almost 80 percent) of people live on agriculture the finding is not surprising. However, the point to be noted is that despite such a high dependency on agriculture it is mostly subsistence farming. Agriculture does not provide entrepreneurial opportunity because of its subsistence nature. Hence, many of them enter into other profession which includes entrepreneurial activities in non agriculture businesses. More than one fourth (28) of respondents mentioned that their fathers" profession was business. This indicates the notion that father influences the choice of profession. It becomes natural choice for an individual to choose the profession of his/her father. Hence, if one's father is in business it becomes easy to either inherit the same business or to start a new business for the individual.

This is so because the entrepreneur has an already established network of people and institutions created by father to receive necessary support for the enterprise. It is also interesting to note that about same number of respondents (25.7percent) mentioned that their fathers' profession was service which included both government and private jobs. Instead of selecting government or private job as an option these people had chosen business. This might be because of two reasons. The first is that, both government and private sector jobs, beside few exceptions, do not offer very attractive salaries and benefits therefore making it not so attractive. Second, perhaps many of the children of people in jobs become eager to find something new for them. These reasons might have led these people into entrepreneurship.

Therefore, it was essential to assess the influence of the family, especially of the father in individuals in their choice of entrepreneurship. For this purpose the profession of father was asked to the respondents. The mean value of the test was 4.0169 which portrays that people whose fathers were in business have high chance of becoming entrepreneurs. However, the mean value of people from other parental profession is less than 3 which 
indicates that the effect of their father is less in their entrepreneurial orientation. It is interesting to note that those entrepreneurs who mentioned that their father's were farmers also told that they thought their father had influenced them to become entrepreneurs. Kruskal Wallis test was conducted to see whether there is any difference between the ranks given by entrepreneurs on whether they thought that their choice of profession was guided by their father's profession. The Chi square value was KW 25.635 and P value was .000. This indicates that there was a significant difference in individuals choosing entrepreneurship as a profession as influenced by their fathers‘ profession.

Nepalese society is traditional where overwhelming majority of women still is involved in the household activities full time. In fact, they are expected to do so in most of the families. Adult men are supposed to earn for the living and support their wives, children and ageing parents. Hence, Nepalese women are not much in the workforce and businesses. However, their role in agriculture is really valuable. They work hard, especially in villages in their farm which does not give them a direct return such as wages and salaries.

\section{Table 2 Influence of mothers' profession on entrepreneurship}

\begin{tabular}{|l|c|c|}
\hline \multicolumn{1}{|c|}{ Mothers' profession } & Frequency & Percent \\
\hline Housewife & 152 & 69.7 \\
\hline Business & 8 & 3.7 \\
\hline Agriculture & 52 & 23.9 \\
\hline Service & 5 & 2.3 \\
\hline Others & 1 & 0.5 \\
\hline Total & 218 & 100.0 \\
\hline
\end{tabular}

Therefore, as presented in Table 2it was natural to find that more than two third (69.7percent) of mothers of the respondents were housewives. This indicates that mothers ${ }^{6}$ profession had no direct influence in their children becoming entrepreneurs. About a quarter of (23.9 percent) entrepreneurs mentioned that their mothers' profession was agriculture. The reason is obvious and should be related with the above discussions in fathers' profession that Nepalese population still largely is dependent upon agriculture. Only a small number (3.7 percent) of entrepreneurs mentioned their mothers ' profession was business. Similarly, small number of respondents (2.3 percent) told that their mothers were involved in service which included both public and private institutions. This is again obvious in the given context where Nepalese women are not much involved in activities other than household chores. However, this trend is changing slowly and more and more women are entering into workforce as well as in business. This is visible especially in urban Nepal where one can find good number of women involved in many professions. Therefore, it should be possible that more women will be found in entrepreneurship in future in Nepal. 123

The influence of mother's profession in the choice of entrepreneurship was assessed. The mean value (4.000) shows that entrepreneurs who told that their mothers " profession was business thought that their choice of entrepreneurship was highly affected by their mother"s profession. It is interesting also to note that those entrepreneurs who told their mothers 
were housewives believed that they were influenced by their mothers while entering into entrepreneurship. This is indicated by the mean value 3.2667 which is in the higher side of continuum. Even entrepreneurs whose mothers were farmer also told in good numbers (mean value 2.8269) that their mother had affected their choice of profession. Only those who mentioned their mothers' profession as service or others thought the influence was weak which is indicated by a mean value of 2.000 . When Kruskal Wallis test was conducted to compare the difference in ranks given by people with different maternal profession the Chi square value was 8.632 and $P$ value of .035 which indicated insignificant difference across the profession. Therefore, though mean value indicates the influence of mothers profession but the tests indicates otherwise. Hence the finding should be taken carefully.

It was essential to assess the influence of family in entrepreneurship. The purpose was to assess the role the grandfather played while choosing a profession by entrepreneurs. Hence, professions of grandfather of entrepreneurs were recorded and presented in Table 3.

Table 3 Role of grandfathers' profession in choice of a profession of respondents

\begin{tabular}{|l|c|c|}
\hline \multicolumn{1}{|c|}{ Grand fathers' profession } & Frequency & Percent \\
\hline Business & 30 & 18.9 \\
\hline Farmer & 102 & 64.1 \\
\hline Service & 16 & 10.1 \\
\hline Others & 11 & 6.9 \\
\hline Total & 159 & 100.0 \\
\hline
\end{tabular}

As in father's and mother's cases, it was found that large number (64.1 percent) of entrepreneurs mentioned their grandfathers" profession as farmer. This once again reflects the dominance of agriculture in the Nepalese society. Only small number (18.9 percent) of respondents told that their grandfathers were in business. Another small number (10.1 percent) of them mentioned that their grandfathers" profession was service. These show that entrepreneurship is generally not a profession inherited by majority of the respondents.

So as to assess the influence of grandparents among respondents to make them become entrepreneurs, data was collected about their grandfather's profession. The highest mean of 4.1000 was given by those entrepreneurs who mentioned that their grandfather's profession was business. It seems that some of them have inherited entrepreneurship from their family tradition. However, it was also found that the mean rank given by those whose grandfathers were in farming also was near the middle of the continuum. This is an interesting indication that regardless of their grandfathers" professions many younger generations of Nepalese people are taking entrepreneurship as a profession. This is a good sign for the future economic development of the country. When Kruskal Wallis test was run to compare the difference in the ranks given by entrepreneurs with different grandparental profession the Chi square value was 15.216 and $\mathrm{P}$ value was .002 which indicates that there was significant difference in the ranks given by entrepreneurs based on their grandfathers" professions. 


\subsection{Role of the family and self in providing inspiration in becoming entrepreneur}

The inspiration of the family members in entrepreneurship was assessed through a question which asked the respondents to mention about whom in the family encouraged them to become an entrepreneur. Both men and women entrepreneurs were asked to choose the person who influenced them to enter into this profession.

Self inspiration was found to the major factor in respondents becoming entrepreneurs. This is an indication that people choose their profession on their own to some extent though it is also true that the family tradition too plays some role in this which is even more so in people making entrepreneurship as choice of profession. Therefore, it can be believed that people's ability to take risk as well as innovate lead them to entrepreneurship. While the respondents were asked further to mention about other family members ‘ role to inspire them besides their own inspirations, male entrepreneurs told that their father had inspired them into entrepreneurship.

When women entrepreneurs were asked the same question they told that the most important person to inspire them into entrepreneurship was their husbands. Out 51 women entrepreneurs 20 mentioned that their husbands provided necessary inspiration to them for their becoming entrepreneurs. Some of entrepreneurs told that their brothers were their inspiration for them to become entrepreneur. Other family members such as grandparents, mother, and sisters have inspired respondents to become entrepreneur in limited cases only. All this shows that the role of father (for both men and women) and husband (for women) is really strong for providing inspiration to become entrepreneur.

The family background, whether it was nuclear or joint family plays some role in entrepreneurship. People from both types of families were doing entrepreneurial activities. Similarly, both men and women were found involved in entrepreneurship. However, their choice of businesses was not much affected by their gender. People from different caste groups also have the view that their choice of business was nothing to do with their caste.

Parental profession has some effect in the choice of entrepreneurship as a profession. The role of father was more influential. The influence of mother and grandfather was not so strong. Birth sequence of the person also was somewhat related to choice of the entrepreneurship. Many of the entrepreneurs were first child of their families. This indicated that those who have to look after their family tend to find entrepreneurship as their choice of profession. The inspiration from the family member also played some role in people being entrepreneur. However, self inspiration was the major factor among the respondents.

\section{Conclusions and Recommendations}

Parental profession plays an important role in selecting a profession. This is truer in Nepalese society. Especially the fathers play as a role model for their children and also have strong influence over their children while choosing a profession. The findings of the study show that nearly one third of the entrepreneurs had their father in some kind of business which might have affected the choice of entrepreneurship as a profession by them. This finding is in line with many studies which have concluded the percentage of entrepreneurs who have parents (mainly fathers) who are (or had been) entrepreneurs is 
higher than that of the general population (Bird, 1993; Buttner, 1993).

It was important to note that those entrepreneurs who said that their mothers were housewives believed that they were influenced by their mothers while entering entrepreneurship. Only those who mentioned their mothers" profession as service or others thought the influence was weak. Though mean value indicates the influence of mothers profession but the tests indicates insignificant relation of the choice of entrepreneurship and their mothers" profession which asks for care while coming into any definite conclusion in this matter.

Entrepreneurship is generally not a profession inherited by majority of the respondents. This also indicates that entrepreneurship is a new profession and there is a large number of first generation of entrepreneurs covered in the study. The finding indicates seems that some of them have inherited entrepreneurship from their family tradition. However, it was also found that the mean rank given by those whose grandfathers were in farming also was near the middle of the continuum. This is an interesting indication that regardless of their grandfathers' professions many younger generations of Nepalese people are taking entrepreneurship as a profession. This is a good sign for the future economic development of the country.

Many people take inspiration from their family members or others while selecting a profession. Self-inspiration was the first important factor mentioned by respondents which influenced them become entrepreneurs. This is an indication that people choose their profession mostly on their own inspiration.

\section{BIBLIOGRAPHY}

Aldrich, H. E., \& Cliff, J. E. (2003). The pervasive effects of family on entrepreneurship: toward a family embeddedness perspective. Journal of Business Venturing, $18,573-596$.

Arregle, J. L., Hitt, M. S., Sirmon, D. G., \& Very, P. (2007). The development of organizational social capital: attributes of family firms. Journal of Management Studies 44(1), 73-95.

Chang, E. P. C., Chrisman, J. J., Chua, J. H., \& Kellermanns, F. W. (2008). Regional economy as a determinant of the prevalence of family firms in the United States: A preliminary report. Entrepreneurship Theory and Practice, 32 (3), 559-573.

Discua-Cruz, A. D., Howorth, C., \& Hamilton, E. (2013). Intra-family entrepreneurship: The formation and membership of family entrepreneurial teams. Entrepreneurship Theory and Practice, 37 (1), 17-46.

Dyer, G. W., \& Handler, W. (1994). Entrepreneurship and family business: Exploring the connections. Entrepreneurship Theory and Practice 19(1): 71-83.

Dyer, W. G. (2006). Examining the 'family effect' on firm performance. Family Business 
Review, 19(4), 253-273.

König, A., Kammerlander, N., \& Enders, A. (2013). The family innovator's dilemma: How family influence affects the adoption of discontinuous technologies by incumbent firms. Academy of Management Review, 38(3), 418-441.

La Porta, R., Lopez-de-Silanes, F., Shleifer, A., \& Vishny, R. (1999). The quality of government. Journal of Law, Economics and Organization , 15(1), 222-279.

Nordqvist, M., \& Melin, L. (2010). Entrepreneurial families and family firms. Entrepreneurship and Regional Development, 22(3-4), 211-239.

Thomas, A. S. (2000).A case for comparative entrepreneurship: Assessing the relevance of culture. Journal of International Business Studies, 31(2), 287.

Rogof, E. G., \& Heck, R. (2003). Evolving research in entrepreneurship and family business: Recognizing family as the oxygen that feeds the fire of entrepreneurship. Journal of Business Venturing, 18(5),559-566.

Ruef, M. (2010). The entrepreneurial group: Social identities , relations , and collective action . Princeton and Oxford: Princeton University Press.

Ruef, M., Aldrich, H. E., \& Carter, N. M. (2003). The structure of founding teams: Homophily, strong ties, and the isolation among U.S. entrepreneurs. American Sociological Review, 68, 195-222.

Villalonga, B., \& Amit, R. (2009). How are U.S. family firms controlled? The Review of Financial Studie, 22(8), 3047-3091.

Zivetz, L.(1992).Private enterprise and the state in modern Nepal. Madras: Oxford University Press. 